\title{
The Effect of Age on Fracture Risk: A Population-Based Cohort Study
}

\author{
Wenbin Liang and Tanya Chikritzhs \\ National Drug Research Institute, Curtin University, GPO Box U1987, Perth, WA 6845, Australia \\ Correspondence should be addressed to Wenbin Liang; w.liang@curtin.edu.au
}

Received 15 April 2016; Accepted 12 May 2016

Academic Editor: F. R. Ferraro

Copyright ( 2016 W. Liang and T. Chikritzhs. This is an open access article distributed under the Creative Commons Attribution License, which permits unrestricted use, distribution, and reproduction in any medium, provided the original work is properly cited.

\begin{abstract}
Aim. To precisely estimate the effect of age on the risk of fracture hospitalisation among the Western Australia population over the life course. Methods. This population-based cohort study used hospital data on fractures for the period January 1991 to January 2013 among Western Australians born between 1915 and 1990. Results. The average incidence rates (per 10,000 person-years) of fracture hospitalisation (95\% confidence interval) were 50.12 (49.90, 50.35), $55.14(54.82,55.48)$, and $45.02(44.71,45.32)$ for both males and females, males only, and females only, respectively. The age-specific rate of fracture hospitalisation (in natural logarithm form) in adults ( $>18$ years) was well predicted by age at its 1st, 2 nd, and 3 rd power in males with an adjusted $R$-squared of 0.98 and $p<0.001$. For females, the trend was also well predicted by its 1st and 2nd powers (the 3rd power term of age was removed due to its $p$ value $>$ 0.8 ) with an adjusted $R$-squared of 0.99 and $p<0.001$. Conclusions. Overall trends in age and gender specific risk of fracture among the Western Australian population were similar to estimates reported from previous studies. The trend in fracture hospitalisation risk over the life course can be almost fully explained by age.
\end{abstract}

\section{Introduction}

Injuries are a major cause of morbidity and mortality in both developing and developed countries, while fractures account for a substantial proportion of injuries [1-3]. Fractures not only cause temporary or permanent physical disability but may also impair the overall life quality and mental health of affected individuals $[4,5]$ and lead to significant burden on healthcare systems as well as family carers [1,5-7]. Age and gender are important factors that influence the risk of fractures [8]. A number of European epidemiological studies have focused on the effects of age and gender among adult [9-14] and child [15-18] populations. There are limited data available on the overall lifetime incidence rate of fracture among the general Australian population [19, 20], and the majority of Australian studies have focused on site specific fractures [20-22]. In this study, we aim to investigate the effect of age and gender on the risk of fracture among the Western Australian population and apply age to model fracture risk over the life course with good precision.

\section{Method}

This population-based cohort study used hospital separation data on injuries and fractures due to injuries for the period January 1991 to January 2013 among Western Australians (WA) born between 1915 and 1990 (participants are 75-0 years old at baseline). Data were extracted from the WA Hospital Morbidity Data System by the WA Department of Health. The WA Hospital Morbidity Data System included separations from all WA public and private acute hospitals [23]. Hospitalisation records were coded using ICD-9 between 1990/91 and 1998/99 (fiscal year) and ICD-10 classification system from $1999 / 00$. In this study primary diagnosis, codes including ICD-9 codes (800-829) and ICD-10 codes (S12, S22, S32, S42, S52, S62, S72, S82, S92, T02, T08, T10, and T12) were used to identify fracture cases, whereas External Causes of Injury and Poisoning (ICD-9) and External Causes of Morbidity and Mortality (ICD-10) were used to define hospitalisations due to injuries (rather than pathologic causes). Annual estimates of WA gender and age-specific residential populations over the 


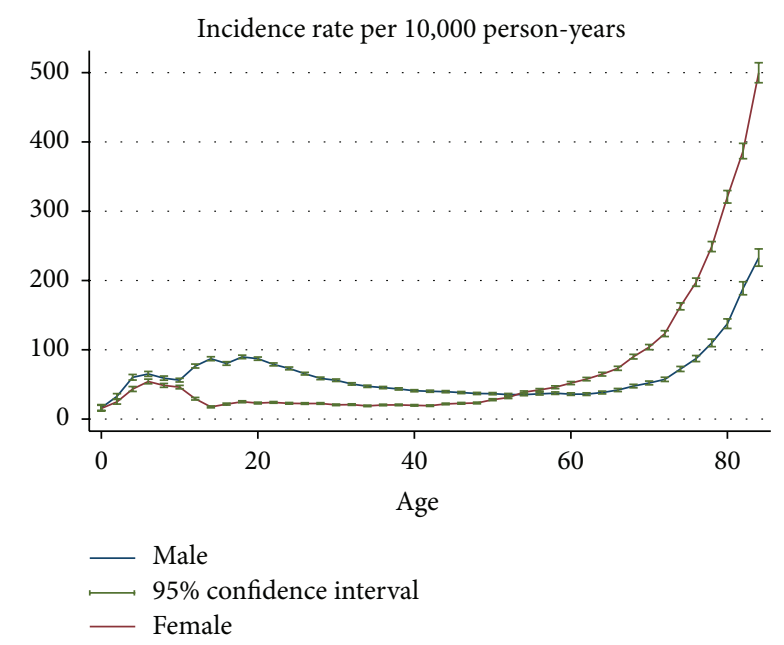

FIGURE 1: Gender-age-specific incidence rates of fracture hospitalisation.

observation period were provided by the Australian Bureau of Statistics (ABS).

\section{Data Analysis}

In the descriptive analysis, overall and age-specific incidence rates of fracture were estimated by age between 0 and 85 years in 2-year intervals, separately for males and females. The age-specific incidence rates were then used to compute the cumulative risk of having at least one fracture hospitalisation for males and females. The risk of hospitalisation due to any injury (including nonfracture cases) was also described using gender and age-specific incidence rates. To investigate how the effects of gender may change over the lifetime, agespecific female-to-male incidence rate ratios were estimated. Log-linear models with age, age to the power of 2, and age to the power of 3 as predictors were fitted based on the agespecific risk of fracture for ages 18 to 85 , separately for males and females.

\section{Results}

Overall 193,434 cases of fracture hospitalisation arose from $38,591,627$ person-years of observation. The average incidence rates (per 10,000 person-years) of fracture hospitalisation (95\% confidence interval) were $50.12(49.90,50.35)$, $55.14(54.82,55.48)$, and $45.02(44.71,45.32)$ for both males and females, males only, and females only, respectively. The incidence rates (per 10,000 person-years) for overall injury hospitalisations ( $95 \%$ confidence interval) were 151.24 $(150.85,151.63), 168.82$ (168.2, 169.40), and 133.37 (132.85, 133.89) for both males and females, males only, and females only, respectively. The overall fracture-to-injury risk ratio was about 1 to 3 .

The gender-age-specific incidence rates of fracture hospitalisation are shown in Figure 1. Figure 2 provides a close-up illustration of the risk pattern for ages 18-50 years. Overall, the risk of fracture increased continuously up to 8 years

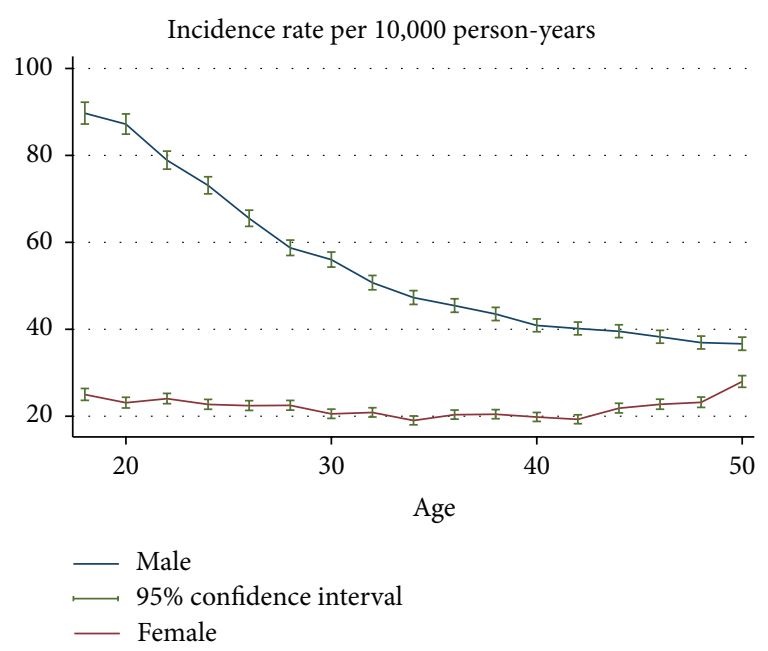

FIGURE 2: Gender-age-specific incidence rates of fracture hospitalisation for the age between 18 and 50 years.

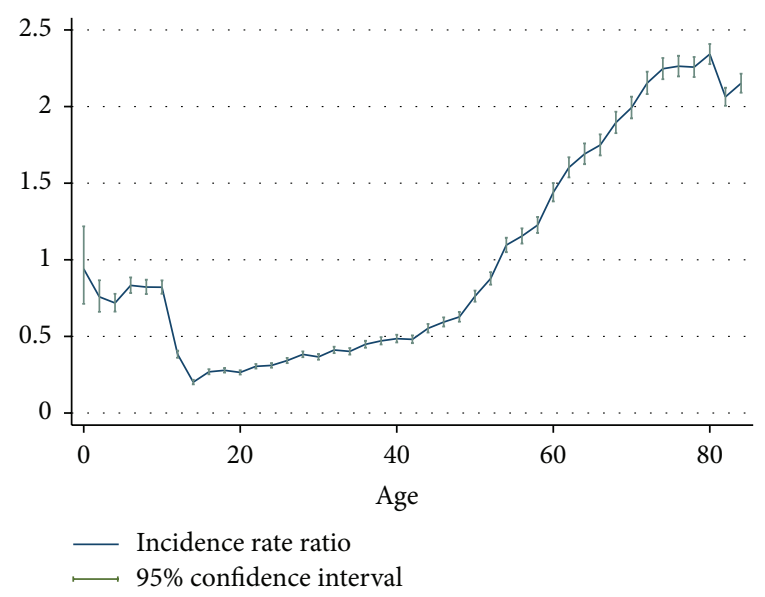

FIgUre 3: Age-specific female-to-male incidence rate ratios of fracture hospitalisations.

of age and remained unchanged between 6 and 11 years for both genders. From the age of 12, the risk of fracture increased gradually until the age of 19 in males, whereas the risk of fracture decreased over adolescent period for females. The risk of fracture declined in males from age 20 years through to the late 40s; among females, however, the risk of fracture began increasing from about the age of 42 years. Up to the age of 54 years, the incidence rate of fracture was consistently higher for males compared to females; thereafter, female rates exceeded male rates and remained higher to the end of the observation period. Accordingly, the age-specific female-to-male incidence rate ratios of fracture increased from the age of 20 (Figure 3 ). The pattern of age-specific injury hospitalisation rates appeared to be similar between the two genders, except for ages 55 to 65 , when the risk of injury continuously increased in females but remained largely unchanged in males (Figure 6).

The age-specific rate of fracture (in natural logarithm form) in adults ( $>18$ years) was well predicted by age at its 
TABLE 1: log-linear model of age-specific fracture hospitalisation rates.

\begin{tabular}{lc}
\hline Gender & Model and estimated coefficients \\
\hline Male & $\ln ($ risk of fracture $)=4.648261+0.0158851 \times$ age $^{-0.0017527 \times \text { age }^{2}+0.0000198 \times \text { age }^{3}}$ \\
Female & $\ln ($ risk of fracture $)=4.405889-0.0843678 \times$ age $^{2}+0.0012531 \times$ age $^{2}$ \\
\hline
\end{tabular}

ln: natural logarithm.

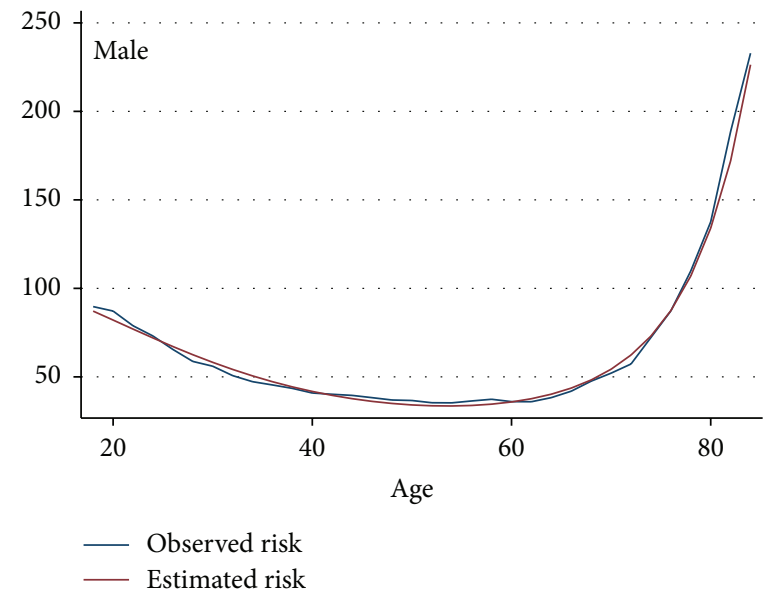

(a)

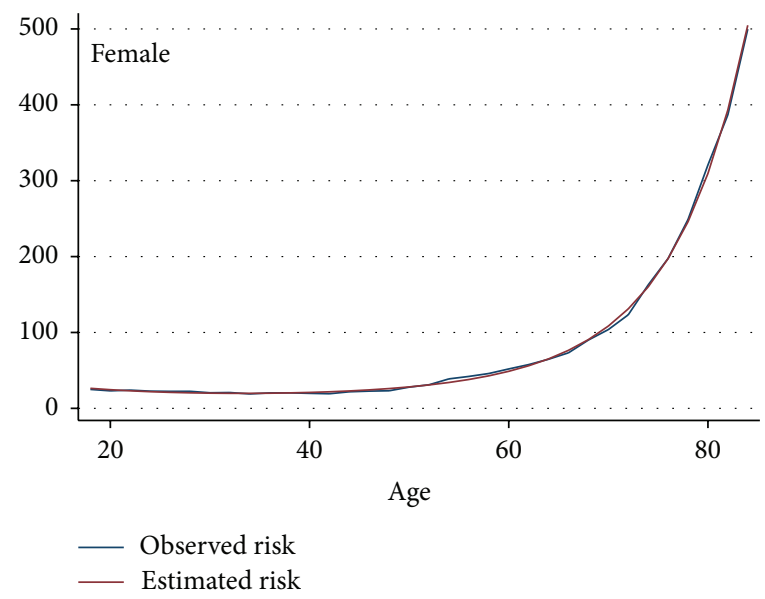

(b)

FIGURE 4: Comparison between observed gender-age-specific incidence rates of fracture hospitalisation and estimates from log-linear model (per 10,000 person-years).

1st, 2nd, and 3rd power in males with an adjusted $R$-squared of $0.98(p<0.001)$. For females, the trend was also well predicted by its 1 st and 2 nd powers (the 3 rd power term of age was removed due to its $p$ value $>0.8)$ with an adjusted $R$-squared of $0.99(p<0.001)$ (see Table 1). Comparison between the observed incidence rates of facture and estimates from the model are shown in Figure 4.

For males and females, respectively, the cumulative risk of having at least one fracture hospitalisation due to injury was $11.8 \%$ and $6.3 \%$ by the age of 18 years, increased to $23.8 \%$ and $11.4 \%$ by the age of 45 years and increased again to $37.4 \%$ and $37.6 \%$ by 80 years (Figure 5 ).

\section{Discussion}

This study provided a detailed picture of the risk of fracture hospitalisations among the Western Australia population. Overall trends in age and gender specific risk of fracture were similar to observations from previous studies conducted on other populations [9-14, 20,24]. The relative increase in fracture risk among females compared to males throughout the 20s and 30s (Figure 3) was also evident although this has not been explored in detail in some of the earlier studies $[12,13,19]$. This increasing trend of female-to-male fracture incidence rate ratios appears to be driven by a decrease in risk for males and stable risk for females in that age period (Figure 2). However, the age-specific risk of all injuries appeared to decrease at a similar rate for the two genders (Figure 6), and therefore the increase in female-to-male incidence rate ratio in the 20 s and 30 s is unlikely to be entirely due to reductions in involvement of injury-related activities among males as they mature. The observed gender difference in the age-specific trend of fracture over this age period may be due to sex-specific changes in musculoskeletal fitness. This study also showed that the changes in the probability of fracture in adults over the life course can be expressed as a function of age. This suggests that the variation in fracture risk at different life stages is driven by risk factors (causes) that are determined or strongly associated with age. There is good evidence suggesting that the progression of osteoporosis $[6,25]$, changes in musculoskeletal fitness $[2,26]$, probability of involvement in injury-related behaviours [26, 27], and having certain health conditions $[8,28]$ are dependent on age; however, it is unclear what other factors may underpin the strong association between fracture risk and age, and further research is required.

This study has some limitations. The analyses relied entirely on hospitalisation cases, which do not include fractures that are treated by outpatient services (such as at Emergency Departments and GP clinics) and which may be relatively less severe. In addition, the study is unable to distinguish first ever and secondary fractures. However, strengths of the study include its very large population-based sample, long follow-up period, application of a number of statistical methods, and the provision of detailed estimates of the absolute risks and cumulative risk of facture from birth to 85 years. In addition, this study showed that the trend in 


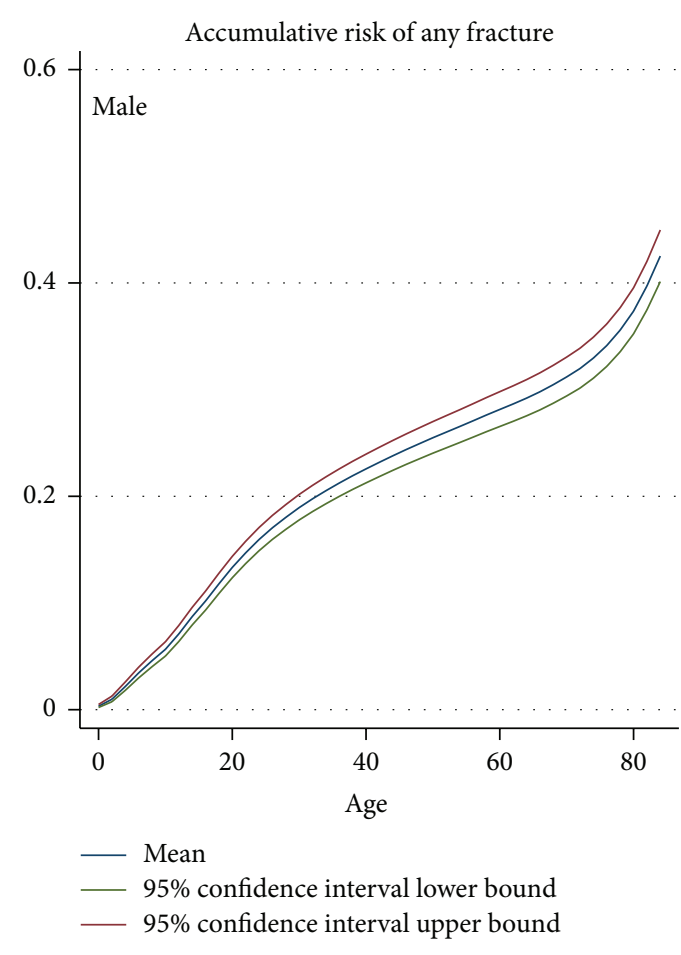

(a)

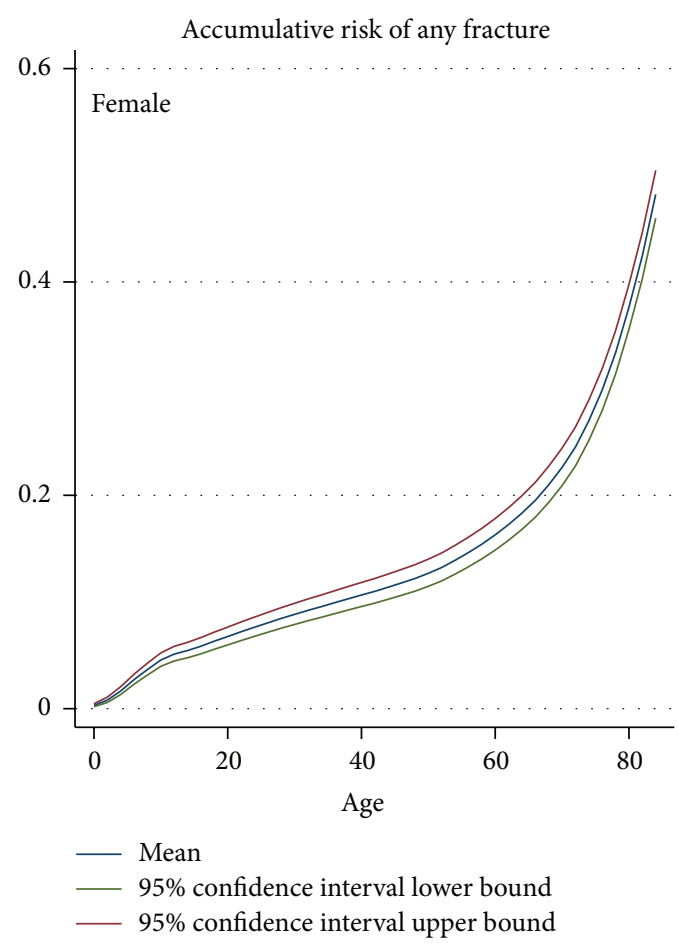

(b)

FIGURE 5: Cumulative risk of having any fracture hospitalisation since birth.

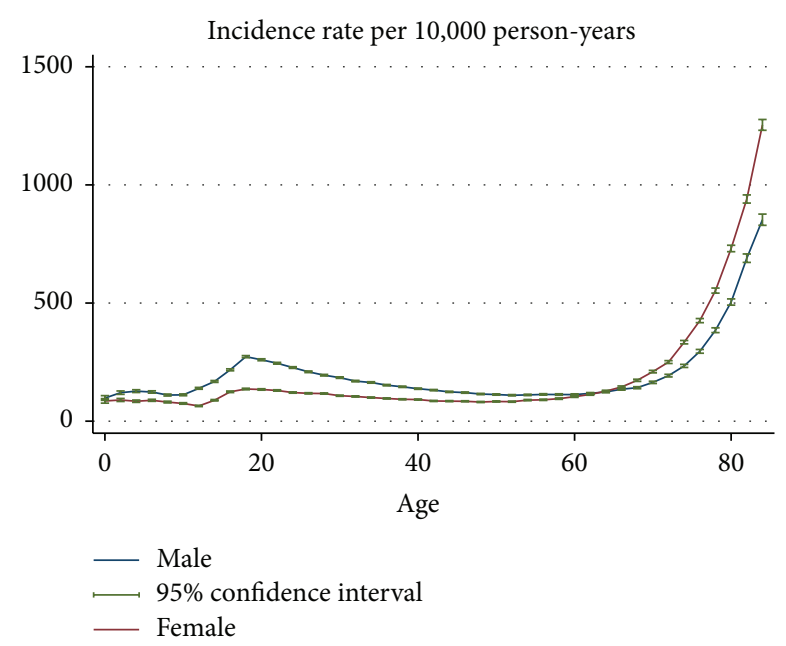

FIGURE 6: Gender-age-specific overall injury hospitalisations rates.

fracture risk over the life course can be almost fully explained (i.e., predicted) by age.

\section{Conclusion}

Overall trends in age and gender specific risk of fracture among the WA population were similar to estimates reported from previous studies. There is a relative increase in fracture risk among females compared to males throughout their $20 \mathrm{~s}$ and 30 s which could not be explained by reductions in injuryrelated activities among males. The trend in fracture risk over the life course can be almost fully explained by age.

\section{Ethical Approval}

This study has been approved by Department of Health Western Australia Human Research Ethics Committee and by Human Research Ethics Committee, Curtin University (approval number NDRI-04-2013).

\section{Competing Interests}

The authors declare that there is no conflict of interests regarding the publication of this paper.

\section{Acknowledgments}

This work was supported by the Australian Government Department of Health and Ageing under the National Drug Strategy's funding of the National Drug Research Institute. This work was also supported by Healthway and the Drug and Alcohol Office, Western Australia. The authors thank the Western Australia Department of Health and Australian Bureau of Statistics for providing the data used in this study.

\section{References}

[1] S. Polinder, W. J. Meerding, S. Mulder et al., "Assessing the burden of injury in six European countries," Bulletin of the World Health Organization, vol. 85, no. 1, pp. 27-34, 2007. 
[2] C. Mock and M. N. Cherian, "The global burden of musculoskeletal injuries: challenges and solutions," Clinical Orthopaedics and Related Research, vol. 466, no. 10, pp. 2306-2316, 2008.

[3] T. Vos, A. D. Flaxman, M. Naghavi et al., "Years lived with disability (YLDs) for 1160 sequelae of 289 diseases and injuries 1990-2010: a systematic analysis for the Global Burden of Disease Study 2010," The Lancet, vol. 380, no. 9859, pp. 21632196, 2012.

[4] I. A. Harris, J. M. Young, B. B. Jalaludin, and M. J. Solomon, "The effect of compensation on general health in patients sustaining fractures in motor vehicle trauma," Journal of Orthopaedic Trauma, vol. 22, no. 4, pp. 216-220, 2008.

[5] S. Boufous and A. Williamson, "Work-related injury in NSW hospitalisation and workers' compensation datasets: a comparative analysis," Australian and New Zealand Journal of Public Health, vol. 27, no. 3, pp. 352-357, 2003.

[6] A. D. Woolf and B. Pfleger, "Burden of major musculoskeletal conditions," Bulletin of the World Health Organization, vol. 81, no. 9, pp. 646-656, 2003.

[7] P. Mujuru, L. Singla, J. Helmkamp, J. Bell, and W. Hu, "Evaluation of the burden of logging injuries using West Virginia workers' compensation claims data from 1996 to 2001," American Journal of Industrial Medicine, vol. 49, no. 12, pp. 1039-1045, 2006.

[8] J. A. Kanis, H. Johansson, A. Oden, and E. V. McCloskey, "Assessment of fracture risk," European Journal of Radiology, vol. 71, no. 3, pp. 392-397, 2009.

[9] M. R. Brinker and D. P. O'Connor, "The incidence of fractures and dislocations referred for orthopaedic services in a capitated population," The Journal of Bone \& Joint Surgery-American Volume, vol. 86, no. 2, pp. 290-297, 2004.

[10] B. R. Singer, G. J. McLauchlan, C. M. Robinson, and J. Christie, "Epidemiology of fractures in 15,000 adults: the influence of age and gender," The Journal of Bone \& Joint Surgery-British Volume, vol. 80, no. 2, pp. 243-248, 1998.

[11] L. J. Donaldson, A. Cook, and R. G. Thomson, "Incidence of fractures in a geographically defined population," Journal of Epidemiology and Community Health, vol. 44, no. 3, pp. 241-245, 1990.

[12] C. M. Court-Brown and B. Caesar, "Epidemiology of adult fractures: a review," Injury, vol. 37, no. 8, pp. 691-697, 2006.

[13] T. P. van Staa, E. M. Dennison, H. G. M. Leufkens, and C. Cooper, "Epidemiology of fractures in England and Wales," Bone, vol. 29, no. 6, pp. 517-522, 2001.

[14] D. Fife and J. I. Barancik, "Northeastern Ohio trauma study III: incidence of fractures," Annals of Emergency Medicine, vol. 14, no. 3, pp. 244-248, 1985.

[15] E. M. Hedström, O. Svensson, U. Bergström, and P. Michno, "Epidemiology of fractures in children and adolescents: increased incidence over the past decade: a population-based study from northern Sweden," Acta Orthopaedica, vol. 81, no. 1, pp. 148-153, 2010.

[16] P.-H. Randsborg, "Fractures in children: aspects on health service, epidemiology and risk factors," Acta Orthopaedica, vol. 84, no. 350, pp. 1-24, 2013.

[17] P.-H. Randsborg, P. Gulbrandsen, J. Saltyte Benth et al., "Fractures in children: epidemiology and activity-specific fracture rates," The Journal of Bone \& Joint Surgery-American Volume, vol. 95, no. 7, article e42, 2013.

[18] L. Rennie, C. M. Court-Brown, J. Y. Mok, and T. F. Beattie, “The epidemiology of fractures in children," Injury, vol. 38, no. 8, pp. 913-922, 2007.
[19] G. Jones and H. M. Cooley, "Symptomatic fracture incidence in those under 50 years of age in southern Tasmania," Journal of Paediatrics and Child Health, vol. 38, no. 3, pp. 278-283, 2002.

[20] K. M. Sanders, E. Seeman, A. M. Ugoni et al., "Age- and genderspecific rate of fractures in Australia: a population-based study," Osteoporosis International, vol. 10, no. 3, pp. 240-247, 1999.

[21] S. Boufous, C. Finch, S. Lord, J. Close, T. Gothelf, and W. Walsh, "The epidemiology of hospitalised wrist fractures in older people, New South Wales, Australia," Bone, vol. 39, no. 5, pp. 1144-1148, 2006.

[22] A. A. Fisher, E. D. O’Brien, and M. W. Davis, "Trends in hip fracture epidemiology in Australia: possible impact of bisphosphonates and hormone replacement therapy," Bone, vol. 45, no. 2, pp. 246-253, 2009.

[23] C. D. J. Holman, A. J. Bass, I. L. Rouse, and M. S. T. Hobbs, "Population-based linkage of health records in Western Australia: development of a health services research linked database," Australian and New Zealand Journal of Public Health, vol. 23, no. 5, pp. 453-459, 1999.

[24] R. E. Gibson, M. Harden, J. Byles, and J. Ward, "Incidence of falls and fall-related outcomes among people in aged-care facilities in the Lower Hunter region, NSW.," New South Wales Public Health Bulletin, vol. 19, no. 10, pp. 166-169, 2008.

[25] J. A. Pasco, E. Seeman, M. J. Henry, E. N. Merriman, G. C. Nicholson, and M. A. Kotowicz, "The population burden of fractures originates in women with osteopenia, not osteoporosis," Osteoporosis International, vol. 17, no. 9, pp. 1404-1409, 2006.

[26] R. Bahr and T. Krosshaug, "Understanding injury mechanisms: a key component of preventing injuries in sport," British Journal of Sports Medicine, vol. 39, no. 6, pp. 324-329, 2005.

[27] J. M. Conn, J. L. Annest, and J. Gilchrist, "Sports and recreation related injury episodes in the US population, 1997-99," Injury Prevention, vol. 9, no. 2, pp. 117-123, 2003.

[28] L. Z. Rubenstein, "Falls in older people: epidemiology, risk factors and strategies for prevention," Age and Ageing, vol. 35, supplement 2, pp. ii37-ii41, 2006. 


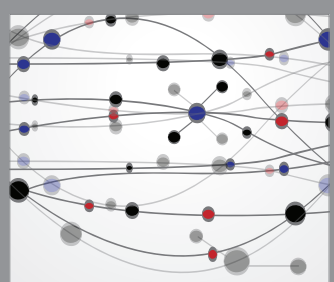

The Scientific World Journal
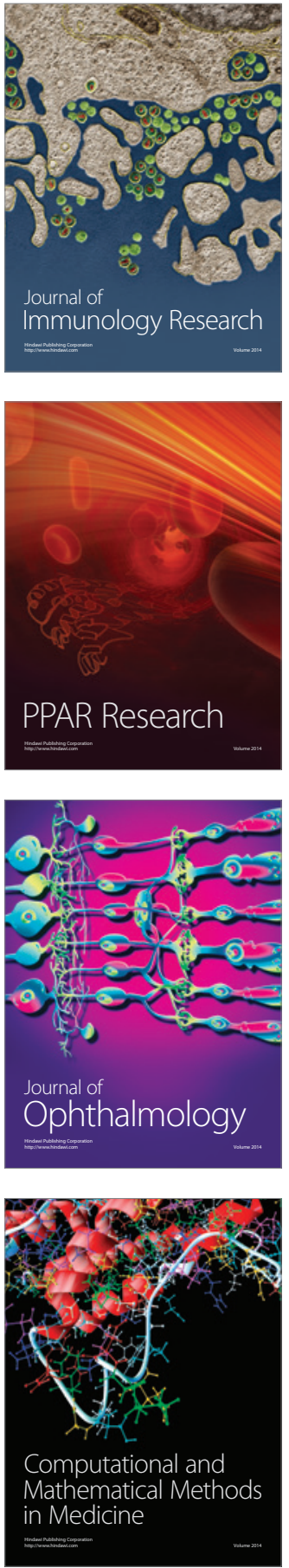

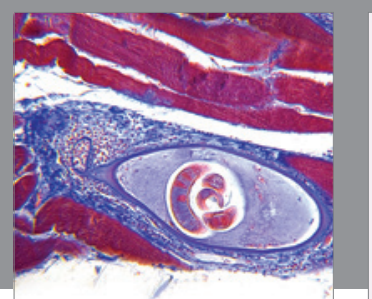

Gastroenterology Research and Practice

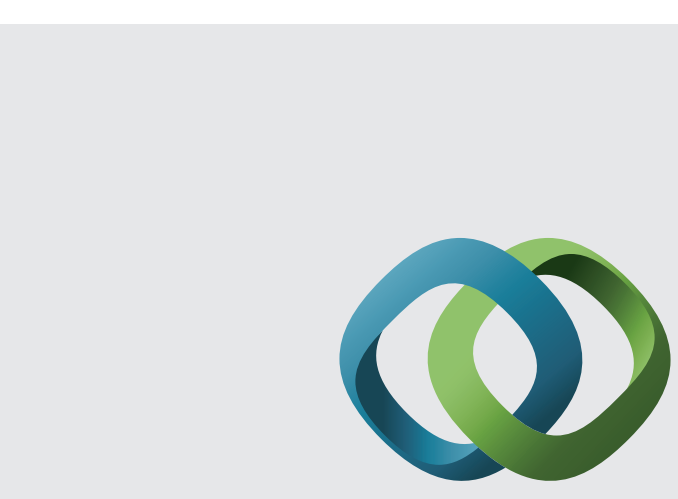

\section{Hindawi}

Submit your manuscripts at

http://www.hindawi.com
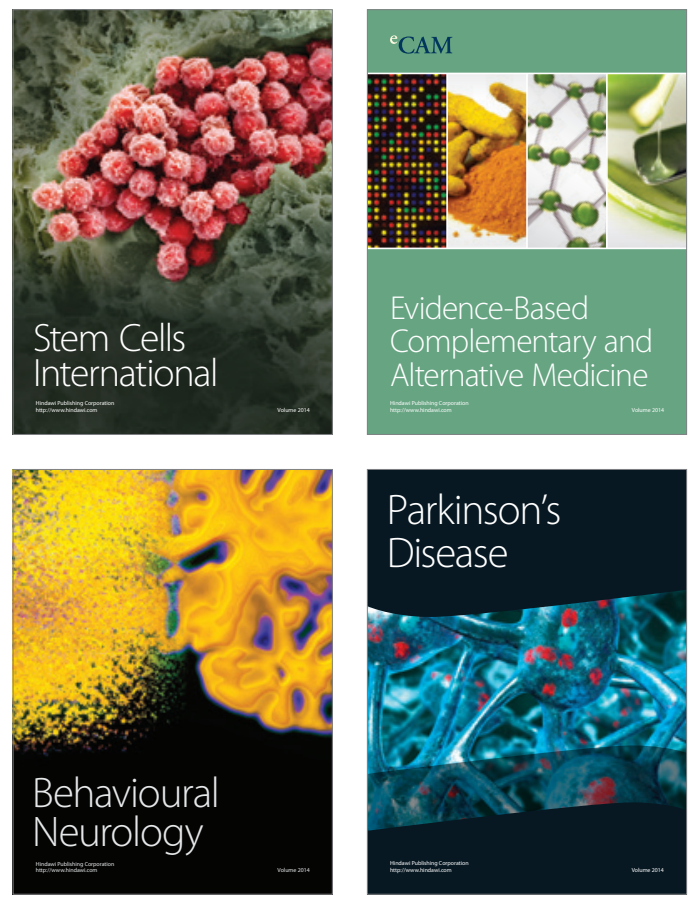
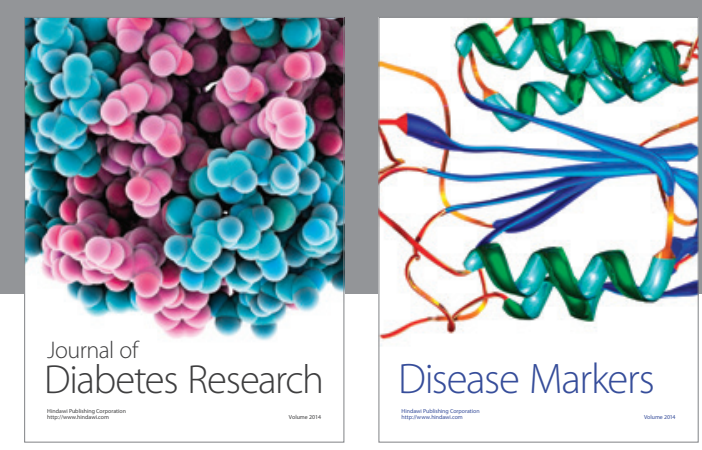

Disease Markers
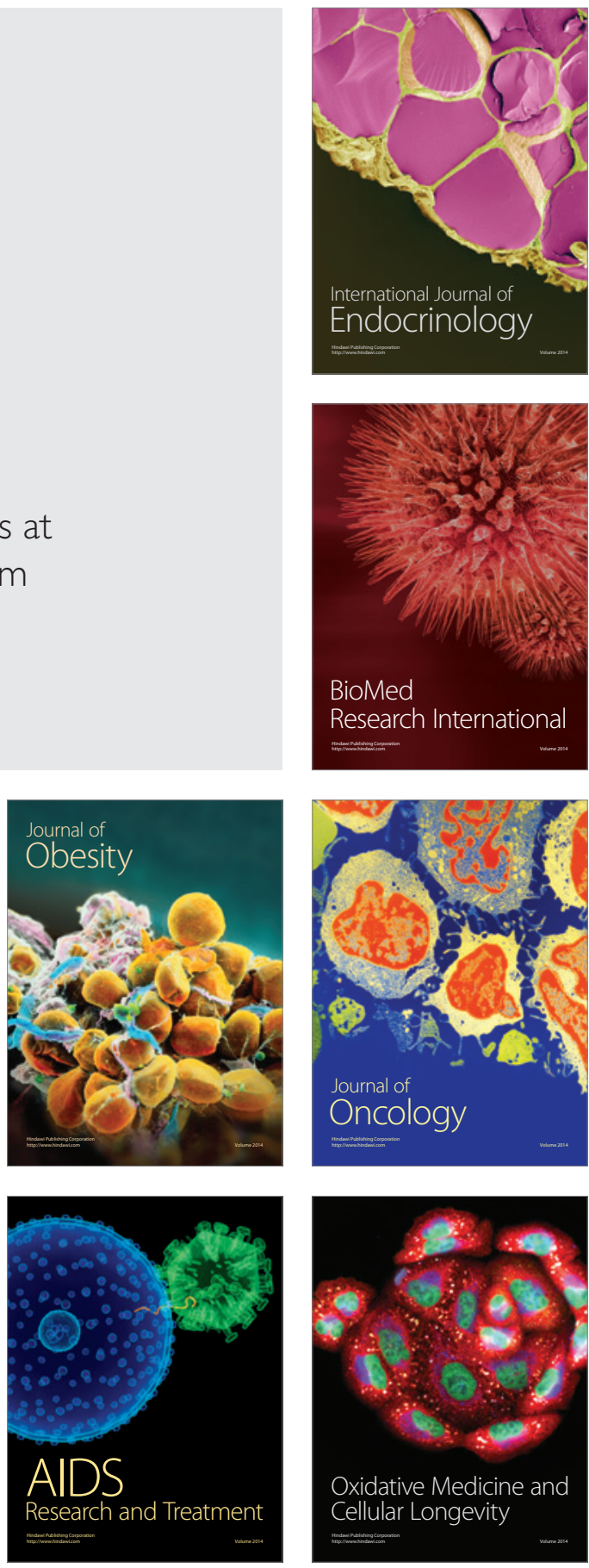